\title{
Blandine Perona, Prosopopée et 'persona' à la Renaissance
}

\section{Maurizio Busca}

\section{(2) OpenEdition \\ Journals}

Edizione digitale

URL: http://journals.openedition.org/studifrancesi/780

DOI: $10.4000 /$ studifrancesi.780

ISSN: 2421-5856

\section{Editore}

Rosenberg \& Sellier

\section{Edizione cartacea}

Data di pubblicazione: 1 agosto 2015

Paginazione: 355-356

ISSN: 0039-2944

\section{Notizia bibliografica digitale}

Maurizio Busca, «Blandine Perona, Prosopopée et 'persona' à la Renaissance», Studi Francesi [Online], 176 (LIX | II) | 2015, online dal 01 août 2015, consultato il 18 septembre 2020. URL : http:// journals.openedition.org/studifrancesi/780; DOI : https://doi.org/10.4000/studifrancesi.780

Questo documento è stato generato automaticamente il 18 settembre 2020.

\section{(c) (i) (9)}

Studi Francesi è distribuita con Licenza Creative Commons Attribuzione - Non commerciale - Non opere derivate 4.0 Internazionale. 


\title{
Blandine Perona, Prosopopée et 'persona' à la Renaissance
}

\author{
Maurizio Busca
}

\section{NOTIZIA}

BLANDINE PERONA, Prosopopée et 'persona' à la Renaissance, Paris, Classiques Garnier, 2013

(«Bibliothèque de la Renaissance», 12), pp. 418.

1 Nel presente studio l'A. si interroga sulle forme e sulle funzioni della prosopopea nelle opere di Erasmo e di quattro autori francesi (Rabelais, Louise Labé, Montaigne, Béroalde de Verville), evidenziandone il ruolo centrale nella definizione dei rapporti fra autore e lettore.

Nella corposa introduzione (pp.7-38), l'A. ripercorre le definizioni antiche della prosopopea elaborate da quei retori latini e greci (Quintiliano, Libanio, Ermogene) i cui trattati saranno poi ripresi e rielaborati nel Rinascimento, e pone le basi metodologiche della sua indagine. Seguono quattro sezioni, la prima delle quali («Le consentement à la prosopopée», pp. 39-127) è dedicata a Erasmo e Rabelais. Di Erasmo l'A. si confronta con una serie di testi teorici (le prefazioni del Novum Testamentum, la Lingua, il De duplici copia e soprattutto il Ciceronianus) che sottopone a una lettura originale, attraverso la quale si delinea uno spazio di connivenza, di convivialità fra autore e lettore; di Rabelais è il Tiers Livre ad essere oggetto di indagine, e soprattutto il prologo, luogo del «pacte de lecture». Per Erasmo come per Rabelais, afferma l'A., la prosopopea è un «miroir imparfait» dell'interiorità autoriale, un travestimento: al lettore il compito di superare la finzione e a intraprendere una ricerca dell'autore dietro i suoi personaggi, per diventare egli stesso portaparola dell'autore. La seconda sezione («Y a-t-il quelqu'un derrière le masque?», pp. 129-200) è dedicata a Louise Labé e alle diverse tipologie di prosopopea cui fa ricorso nelle sue Euvres, dalla costruzione lucianesca del Débat de Folie et d'Amour, all'etopea ovidiana delle Élégies, all'uso retorico tradizionale dell'ode finale. L'A. rileva come, nell'economia dell'opera, la funzione di questo sistema 
composito sia quella di «retirer son autorité à l'auteur qui ne pense plus l'œuvre comme lieu où s'impose une vision juste du monde, la sienne»: la prosopopea servirebbe allora a far arretrare la persona autoriale, esibendo la finzione dell'io lirico delle elegie e dei sonetti. La terza sezione («La prosopopée, truchement rhétorique de l'âme», pp. 201-295) guarda agli Essais di Montaigne considerati nel loro insieme come una grande prosopopea, una sorta di rappresentazione imperfetta dell'autore. Dissimulandosi dietro le molteplici voci che vanno a informare la costruzione retorica della sua persona, l'autore «affranchit le lecteur de l'autorité du texte», invitandolo a dialogare attivamente con l'opera per cogliere i segni dell'adesione (o del rifiuto) autoriale ai personaggi (veri o fittizi) convocati nel discorso. La quarta e ultima sezione («C'est Parole qui parle», pp. 297-373) è dedicata a Béroalde de Verville e al Moyen de parvenir, dialogo nel quale la prosopopea diviene un «masque qui ne cache plus personne»: nel labirinto verbale del Moyen, in cui le prosopopee fungono da «indices de fictionnalité», la denuncia della vanità del linguaggio diviene occasione di complicità fra autore e lettore. 